\title{
Drosophilids (Insecta, Diptera) as Tools for Conservation Biology
}

\author{
Renata Alves da Mata ${ }^{1,3}$, Melodie McGeoch² \& Rosana Tidon,*
}

${ }^{1}$ Núcleo de Controle Biológico, Centro Nacional de Pesquisa de Recursos Genéticos e Biotecnologia - CENARGEN, Empresa Brasileira de Pesquisa Agropecuária - EMBRAPA, Brasília, DF, Brasil

${ }^{2}$ Cape Research Centre, South African National Parks, CP 216, Steenberg, 7947, South Africa

${ }^{3}$ Instituto de Ciências Biológicas, Universidade de Brasília - UnB, Brasília, DF, Brasil

\begin{abstract}
We advocate the use of drosophilid flies as biological models on biological conservation by presenting a case study in the Cerrado at landscape scale. We analyzed the drosophilid assemblage in the Paranã Valley, together with a baseline data from Federal District. We found four different drosophilid assemblages structured in both local and regional scales. Our study confirms the importance of the Paranã Valley as a diversity center, and the urgency in creating reserves in the region to protect its biological uniqueness. Analyzing drosophilid assemblage composition could help for understanding Cerrado biodiversity by perceiving and focusing it in different scales, and therefore, helping for more accurate and efficient reserve selection, design and placement. Drosophilids can be very useful to study the patterns and processes related to biodiversity and also how human activities affect it, permitting the elaboration of efficient conservation strategies, and improving projections about what might happen in the future.
\end{abstract}

Key words: Biodiversity, Brazilian Savanna, Cerrado Biome, Drosophila, Paranã Valley.

\section{Introduction}

Research in insect population and community are important and necessary knowledge in two ways. First, they provide an essential framework for the ecological understanding and advancing, and second, they can help in developing efficient strategies for biodiversity conservation and sustainable development. Invertebrate, in general, are a rich data source for conservation planning and management, as well as for reserves selection and delineation. They respond to finer-grained differences in both habitat and disturbance types, supplying delineation of distinct biogeographical zones, areas of endemism, community types, and precise centers of evolutionary radiation. Therefore, the study of insect assemblages can improve the spatial resolution of conservation planning (Kremen et al. 1993).

Drosophilids have been intensively used in research, producing a vast literature in many biological areas. The family Drosophilidae currently includes more than 4,000 described species (TaxoDros 2010), and according to Powell (1997) no other biological model has received as much attention as the flies of the genus Drosophila. These

\footnotetext{
*Send correspondence to: Rosana Tidon Instituto de Ciências Biológicas, Universidade de Brasília - UnB, CP 04457, CEP 70904-970, Brasília, DF, Brasil

E-mail: rotidon@unb.br
}

flies are small, numerous, have a short life cycle, and are easily collected and manipulated in the laboratory. In majority, drosophilids breed and feed in rotting plant or fungal material with microorganisms, especially yeasts. Some species exploit a very broad range of plants, having evolved to be human commensals and spreading around the world. Other species exploit a very narrow range of breeding sites, being extremely specialized and restricted to a single type of environment (Powell 1997). Knowledge on ecology of most of the neotropical species is still limited compared to that of paleartic species of this group, especially at tropical South America. However, after the 1980's decade, the interest on ecology of these flies has considerably increased, and several studies using drosophilids to investigate ecological questions have been published (Chaves \& Tidon 2008).

The Cerrado biome, also called "Brazilian savanna", is a complex of seasonal savannas that covers most of the interior Brazil. It is the second largest South American biome, with approximately 2 million $\mathrm{km}^{2}$ (Oliveira \& Marquis 2002). This region is one of 34 biodiversity hotspots around the world, because it is extremely endangered and boasts high endemicity (Mittermeier et al. 2005). Cerrado vegetation is very diverse in form, with savannas and forests occurring in the same region, at the same latitude, under the same climatic conditions. This large heterogeneity is the interactive 
product of the seasonality, topography, edaphic features, and climate fluctuations of the Quaternary. This biome combines an interesting ecological and historical context to those studying the complexities of tropical communities conservation. Despite of this, the geographic coverage of existing data is very restricted, and often only a few localities have been sampled adequately (Lewinsohn et al. 2005). Still, this biome has been extensively transformed by large-scale cattle ranching and industrial plantations, such as soybeans. In fact, the idea of central Brazil as a region to be conquered and transformed has been embedded in the Brazilian society for a long time. As a result, the disturbances caused by both urban and agricultural expansion have increasingly been threatening the rich Cerrado biodiversity (Oliveira \& Marquis 2002).

The Paranã Valley, located in the Northeast Cerrado, is considered an area having high value for both scientific studies and conservation (Cavalcanti 1999). It is characterized by the large amount of physiognomies, geomorphologic and vegetation formations that are singular, but still little known (Oliveira \& Marquis 2002). Some previous studies suggested that this region corresponds to a center of diversity and endemicity for the Cerrado biome (Silva 1997, Silva \& Bates 2002). At the same time, these areas suffer intense exploration by the implementation of cattle farms. Consequently, the landscape is becoming extremely fragmented and few areas still remain native. For all these reasons, inventories that allow a better understanding of biodiversity are very urgent for this region.

The use of drosophilids as biological models in biodiversity conservation has been suggested since the 1990 decade (Parsons 1991; Tidon et al. 2003; Ferreira \& Tidon 2005; Mata et al. 2008b; Mata et al. 2010). Here, we get this proposal across by presenting a case study in the Paranã Valley, which was part of a broader inventory project supported by the Brazilian government (MMA/PROBIO). This broader inventory aimed at identifying potential areas to be conserved in this biome. We investigated the drosophilid assemblages of three potential new conservation areas in the Paranã Valley region, and compared these to two protected areas in the Brazilian Federal District. Specifically, we analyzed the similarity in assemblage composition between regions, areas and habitat types to determine the relative importance thereof in causing regional drosophilid diversity.

\section{Material and Methods}

The data presented here included three potential new conservation areas in the Paranã Valley region, and two protected areas located at the Federal District, which is the political administrative area of the Brazilian capital (Figure 1). Together, these data represent three habitats types $(n=13)$ of the Cerrado biome: gallery forests $(n=3)$, seasonal dry tropical forest, (or just dry forests; $\mathrm{n}=4$ ), and savanna-like vegetations $(n=6)$ (Table 1$)$. The drosophilid specimens were captured by traps (10 traps in each site/month) containing banana and orange baits fermented by yeast (Saccharomyces cerevisiae). The samples were collected in August/September and March/April, the year of collections at each place is shown in Table 1. The collected species were identified by identification keys, species description and, in some cases, male terminalia analysis. Details of each sampling designs and methods are described in supplementary material and showed in Table 1 (see also Mata et al. 2008a; Tidon 2006).

Sample-based rarefaction curves for all drosophilids were compiled separately for the three sampling areas in Paranã Valley to access sample representivity (Jackknife 1; EstimateS 7.5; Colwell 2005). Differences in drosophilid assemblages among sampling sites were examined using the non-Metric Multidimensional Scaling (nMDS) based on group averaging and Bray-Curtis similarity measures (Primer v5, Clarke \& Gorley 2001). Abundance data were standardized and forth root transformed prior to analysis (to weigh common and rare species equally). Then the differences in drosophilid assemblages revealed by the nMDS ordination were tested by multivariate community analysis ANOSIM (Primer v5 2001, Clarke \& Gorley 2001). Changes in the proportion between neotropical and exotic species through the different regions and habitat types were examined graphically.

\section{Results}

Fifty-four species of drosophilids (17,287 individuals) were identified in this study, among which 48 are endemic to the Neotropical Region and six are exotics (D. busckii, D. immigrans, D. malerkotliana, D. simulans, Scaptodrosophila latifasciaeformis and Zaprionus indianus (Table 1). The rarefaction curves for two of the three sampled areas approximated an asymptote, whereas the Paranã area is likely to yield more species with future sampling. The nMDS revealed that the assemblages in the three areas in Paranã Valley were more similar to each other than they were to the two areas of the Federal District (Figure 2). In the Paranã Valley, the more open habitat types, the savanna-like vegetations, were grouped together, while the more closed habitats (dry and gallery forests) produced another group. In a similar way, Federal District also showed a local difference between drosophilid assemblages from savannas and gallery forests. In summary, the nMDS ordination showed four different drosophilid assemblages at this landscape scale: 1) seasonal and gallery forests of the Paranã Valley; 2) savanna-like vegetation of the Paranã Valley; 3 ) gallery forests of the Federal District; and 4) savanna-like vegetation of the Federal District (Figure 2). In fact, ANOSIM confirmed the differences among the four assemblages (Global $\mathrm{R}=0.896 ; \mathrm{p}=0.0001$ ). The pair-wise comparisons between assemblages produced high R-values between 0.70 and 1.00 (Figure 2), also revealing the large dissimilarity between these four assemblages. 

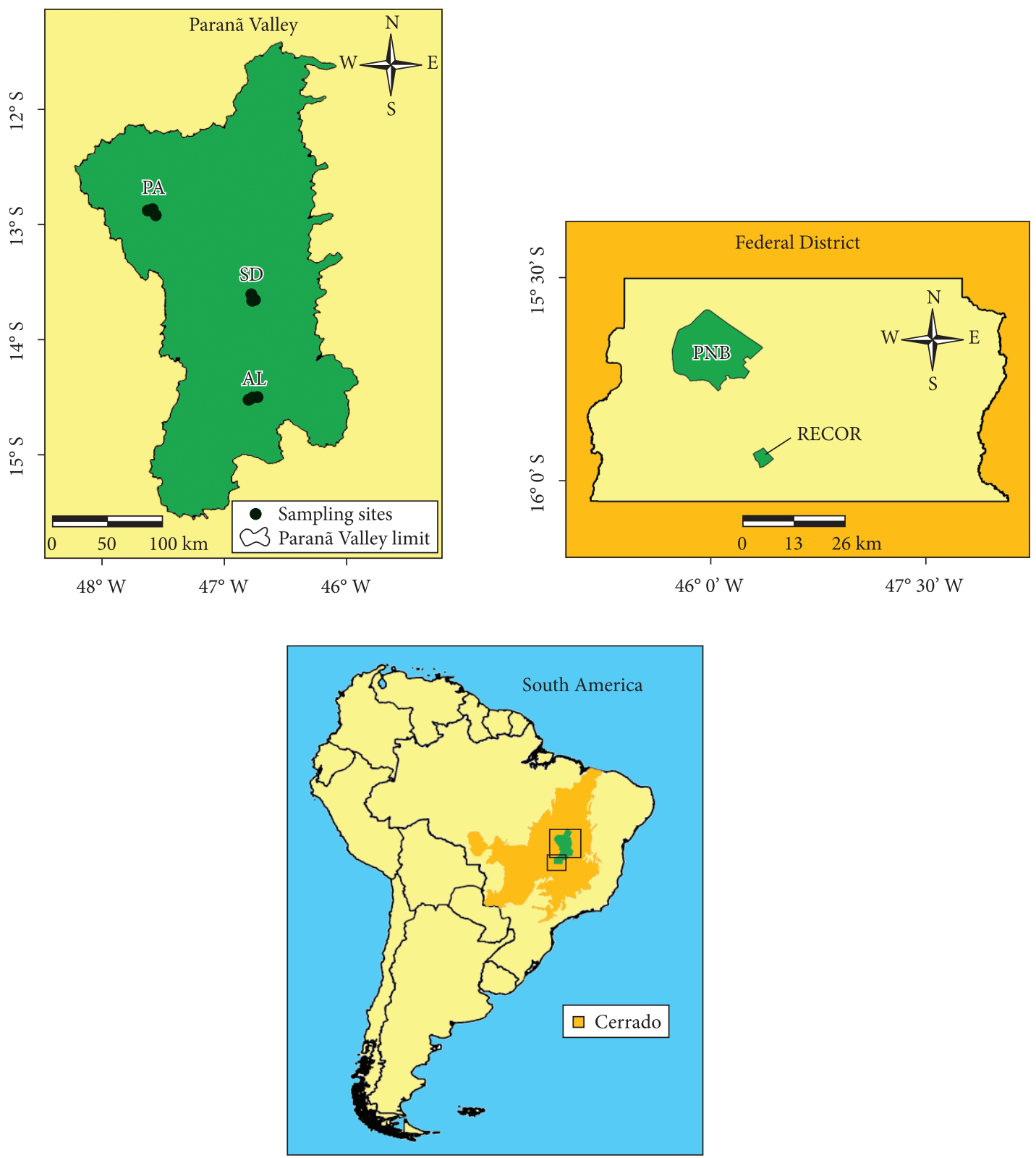

Figure 1. Location of the sampling regions, areas and habitats. Both Reserva Ecológica do IBGE (RECOR) and Parque Nacional de Brasília (PNB) encompassed a gallery forest and a savanna each; Alvorada do Norte (AL) encompassed savannas (2 sites), and dry forest (1 site); São Domingos (SD) encompassed only dry forests (3 sites); and Paranã (PA) encompassed savannas (2 sites) and gallery forest (1 site).

Fourteen species occurred only in the Paranã Valley forests (Table 1), where the proportion of neotropical (between 58 and $88 \%$ ) in relation to exotic species was highest, mainly in dry forests (Figure 3). Five species occurred only in gallery forests of the Federal District (Table 1) that also presented a higher proportion of neotropicals (68-78\%; Figure 3). The Paranã Valley savannas presented six unique species, while the Federal District savannas, presented two (Table 1). The savannas of both regions presented lower percentages of neotropical in relation to the exotic species
(31-55\%; Figure 3). Moreover, all the species that occurred in only one habitat type were neotropicals, while the four exotic species occurred in every habitat type.

\section{Discussion}

The drosophilid assemblages studied here represent the most comprehensive diversity and assemblage-level analyses for drosophilids in the Cerrado biome, providing a baseline for the development of conservation strategies for the 
Table 1. Characterization of the sampling areas and habitat types in the Brazilian Federal District and Paranã Valley region, showing the area's coordinates, sampling periods and data source.

\begin{tabular}{|c|c|c|c|c|c|c|}
\hline Region & Area & Coordinates & Sampling period & Habitat type & $\mathbf{N}$ & Source \\
\hline \multirow{4}{*}{$\begin{array}{l}\text { Federal } \\
\text { District }\end{array}$} & Parque Nacional de Brasília & $15^{\circ} 40^{\prime} \mathrm{S}$ and $47^{\circ} 54^{\prime} \mathrm{W}$ & $08,09 / 2000-03,04 / 2001$ & Gallery forest & 1 & Tidon \\
\hline & & & & Savanna & 1 & 2006 \\
\hline & Reserva Ecológica do IBGE & $15^{\circ} 56^{\prime} \mathrm{S}$ and $47^{\circ} 53^{\prime} \mathrm{W}$ & 08,09/1999-03,04/2000 & Gallery forest & 1 & \\
\hline & & & & Savanna & 1 & \\
\hline \multirow{5}{*}{$\begin{array}{l}\text { Paranã } \\
\text { Valley }\end{array}$} & Alvorada do Norte & $14^{\circ} 48^{\prime} \mathrm{S}$ and $46^{\circ} 49^{\prime} \mathrm{W}$ & & Savanna & 2 & Current \\
\hline & & & & Dry forest & 1 & study \\
\hline & São Domingos & $13^{\circ} 39^{\prime} \mathrm{S}$ and $46^{\circ} 31^{\prime} \mathrm{W}$ & 08/2003-03/2004 & Dry forest & 3 & \\
\hline & Paranã & $12^{\circ} 33^{\prime} \mathrm{S}$ and $46^{\circ} 48^{\prime} \mathrm{W}$ & & Gallery forest & 1 & \\
\hline & & & & Savanna & 2 & \\
\hline
\end{tabular}

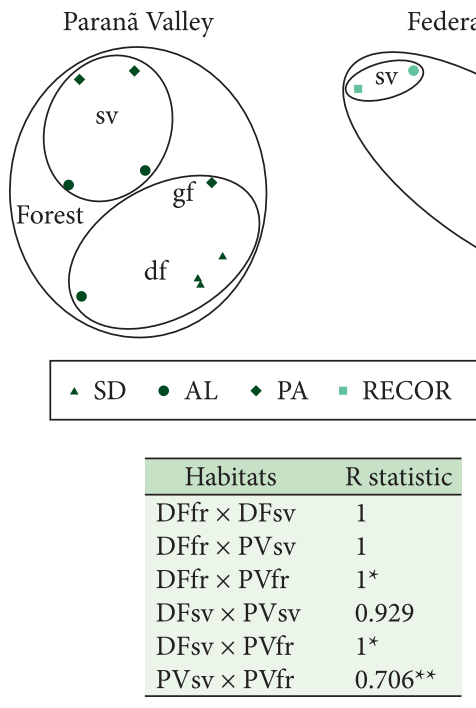

Figure 2. non-Metric Multi-Dimensional Scaling (nMDS) ordination of the abundance of drosophilids in the six sampling areas and habitats types (savanna-like vegetation Paranã Valley, forests Paranã Valley, gallery forests Federal District, and savanna-like vegetation Federal district) (Stress $=0.09 ;{ }^{*} \mathrm{p}<0.05 ;{ }^{* *} \mathrm{p}<0.01$ ). SD. São Domingos, AL. Alvorada do Norte, PA. Paranã, RECOR. Reserva Ecológica do IBGE, and PNB. Parque Nacional de Brasília. gf - gallery forest, df - dry forest, and sv - savanna.

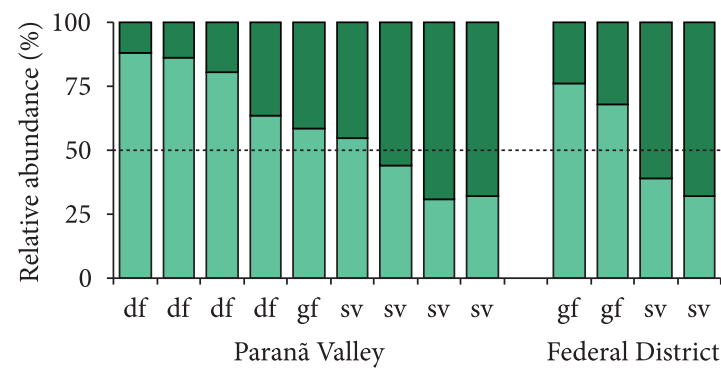

Figure 3. Changes in the relative abundance of the drosophilid assemblages classified as neotropical (light green bars) and exotic species (dark green bars) thorough the sampling sites and regions df - dry forest, gf - gallery forest, and sv - savanna. region. Our data showed that drosophilid assemblages in Cerrado are structured at both local and regional scales. The areas in Paranã Valley region were more similar to each other than they were to the areas of the Federal District region. The assemblages also reflected heterogeneity at a smaller scale, as savannas and forests of each region presented different and characteristic assemblages. Thus, we point out that drosophilid assemblages in the Paranã Valley are unique and important to maintain the regional biodiversity. Lewinsohn et al. (2005) have emphasized that tropical assemblages strongly changes among localities, and that extensive geographic coverage across habitat and ecoregions is essential for diversity and conservation assessments. This effort is necessary to provide spatial and ecological partitioning of species diversity, and help for identifying endemics.

Regular drosophilid inventories in the Cerrado began only at the final years of the 1990's, and currently there are 120 drosophilid species known in the biome, 110 of them endemic to the Neotropical region (Blauth \& Gottschalk 2007; Mata et al. 2008a; Chaves \& Tidon 2008; Roque 2006). The richness of drosophilids in Paranã Valley revealed forty-five species, representing $37.5 \%$ of the species recorded in the Cerrado, and eight new occurrences for the biome (Mata et al. 2008a). The Paranã Valley was pointed as a region presenting high conservation value because of its elevated species richness of several taxa, singularity in species composition, and threat level (Cavalcanti 1999). In fact, Silva and Bates (2002) pointed out three areas as centers of diversity and endemism of birds in the South America Cerrado: Cadeia do Espinhaço, Araguaia Valley, and Paranã Valley. However, there are probably several other areas with high biodiversity that have not been explored or even identified yet. The drosophilid assemblages support the importance of the Paranã Valley as a diversity center.

The forests contained the great diversity and singularity of the regional biota in the Paranã Valley. They encompassed $89 \%$ of the drosophilid diversity of the region, and 33\% of total drosophilid diversity of the Cerrado (with 14 unique species). The savannas showed $62 \%$ of the drosophilid 
diversity of this region and $23 \%$ of total drosophilid diversity of the Cerrado (with 6 unique species). Despite of the higher diversity and singularity of the dry forests, it is important to highlight the role of the other vegetation types of the biome (such as the savannas) to maintain the Cerrado diversity at local scales. The perpetuation of the current human disturbances on the Cerrado, characterized by the substitution of natural habitats for urban and agro-pastoral environments, may lead to invasion of widespread and non-native species, increasing the similarity of originally different communities, and leading to a decrease in local and regional diversity. The process describing this non-random reshuffling of species pools is coined biotic homogenization (Lockwood et al. 2007), referring to an increase in the taxonomic similarity of two or more species pools through time as the result of species invasions and extinctions.

\section{Recommendations}

The results presented here provided information that - together with the results of others groups - can be extremely helpful for establishing efficient management strategies and reserve delineation. Our data on drosophilid assemblage composition clearly show the necessity of perceiving and focusing the Cerrado diversity in a local and regional scale. At a local scale, maintaining forest-savanna mosaic in the reserves' delineation is essential for conserving the local Cerrado diversity. Although forested habitats do not contain all the diversity of the Cerrado, they contribute more to diversity not only because they have more species, but also because they encompass a larger number and proportion of unique and restricted species (Tidon 2006), which generally correspond to the major efforts to conservation due to their vulnerability to extinction. At regional scales, the identification of diversity and endemism centers, as well as ecoregions with conservation values, are essential steps to reserve design and placement. The preservation of the remaining small patches (both savanna and forest), as well as the interconnectivity among them, should have priority in any management plan for the conservation of the Cerrado.

We strongly recommend the establishment of conservation units in the Paranã Valley. Despite of its high conservation value, this region has not a single reserve area protecting its biological resources, and the creation of protected areas remains as a high priority for preserving its biological uniqueness (Silva 1997). Seasonal forests are considered the most threatened tropical ecosystem. They are so strongly fragmented and isolated from each other, that establishing large forest reserves in this region is not possible anymore. Not only do these facts indicate that the conservation value of small seasonal forest patches to both local and regional diversity is extremely high, but also, corroborate that the conservation value of even the remaining small patches should not be ignored. Small patches can increase landscape connectivity and can provide important ecological services and habitat for numerous animal species (Hanski \& Gilpin 1997).

\section{Drosophilids as tools in conservation biology}

Drosophilids have played an important role in the progress of genetics, evolution, and developmental biology (Brookes 2001). More recently, they have been used as models in studies on bioindication (Parsons 1991,1995; Mata et al. 2008b) and also biological invasions (Tidon et al. 2003; Mata et al. 2010). Here, we suggest that drosophilids are great tools for conservation biology. Because these flies are excellent organisms for biological research, they have been widely studied, and therefore, there is available and reliable baseline information about them (Flybase 2010; TaxoDros 2010). Drosophilids are small, numerous, easily sampled and have short life cycles. They are also closely associated to environment variables, being extremely sensitive to changes in their habitats' conditions. This evidence demonstrates their potential as early warning signals of a range of forms of environmental change. This family occurs in almost all environments throughout the globe. Moreover, the local and regional assemblages are composed of phylogenetically related species that can be classified as narrow-ranging or widespread, as native or exotic, as rare or abundant species. These classes of species can co-occur simultaneously, and respond fast and differently to disturbances and management regimes. For example, rare species can be useful for studies related to vulnerability and extinction risk, which may be helpful to select and delineate fine planning and management of reserve areas. On the other hand, abundant, widespread, and non-native species can be helpful in studies focusing biological invasions, by clarifying the ways that specific invasive species invade specific environments. Ultimately, drosophilid flies are good tools to improve the understanding of patterns and processes related to biodiversity, and the understanding of how human activities affect biodiversity at various temporal and spatial scales. Such tools permit the elaboration of more accurate and efficient conservation strategies, as well as the improvement of the projections about what might happen in the future. It would be useful for future studies to test potential mechanisms underlying the restricted and widespread ranges of drosophilid species of Cerrado to assess the relative importance of physiology, resource specialization and biological interactions in maintaining regional diversity of the Cerrado biome.

\section{References}

Blauth ML \& Gottschask MS, 2007. A novel record of Drosophilidae species in the Cerrado biome of the state of Mato Grosso, west-central Brazil. D I S, 90:90-96.

Brookes M, 2001. Fly: an experimental life. London: Weidenfeld \& Nicolson. 
Cavalcanti R, 1999. Ações prioritárias para a conservação da biodiversidade do Cerrado e Pantanal. Belo Horizonte: Conservation International do Brasil.

Chaves NB \& Tidon R, 2008. Biogeographical aspects of drosophilids (Diptera, Drosophilidae) of the Brazilian savanna. Revista Brasileira de Entomologia, 52:340-348.

Clarke KR \& Gorley RN, 2001. PRIMER V5: user Manual/ Tutorial. Plymouth. UK: PRIMIER-E.

Colwell RK, 2005. EstimateS: statistical estimation of species richness and shared species from samples. In User's Guide and application. Available from: http://purl.oclc.org/ estimates.

Ferreira L \& Tidon R, 2005. Colonizing potential of Drosophilidae (Insecta, Diptera) in environments with different grades of urbanization. Biodiversity and Conservation, 14:1809-1821.

Flybase, 2010. A Database of Drosophila Genes \& Genomes. [2010 April 18]. Available from: http://flybase.org/.

Hanski I \& Gilpin M (eds.), 1997. Metapopulation Biology: Ecology, Genetics, and Evolution. San Diego, CA: Academic Press.

Kremen C et al., 1993. Terrestrial arthropod assemblages their use in conservation planning. Conservation Biology, 7:796-808.

Lewinsohn TM, Freitas AVL \& Prado PI, 2005. Conservation of terrestrial invertebrates and their habitats in Brazil. Conservation Biology, 19:640-645.

Mata RA, Roque F \& Tidon R, 2008a. Drosophilids (Insecta, Diptera) of the Paranã Valley: eigth new records for the Cerrado biome. Biota Neotropica, 8:55-60.

Mata RA, McGeoch MA \& Tidon R, 2008b. Drosophilid assemblages as a bioindicator system of human disturbance in the Brazilian Savanna. Biodiversity and Conservation, 17:2899-2916.

Mata RA et al., 2010. Invasive and flexible: niche shift in the drosophilid Zaprionus indianus (Insecta, Diptera). Biological Invasions, 12:1231-1249.
Mittermeier RA et al., 2005. Hotspots Revisited: Earth's Biologically Richest and Most Endangered Terrestrial Ecoregions. Chicago: University of Chicago Press.

Oliveira OS \& Marquis RJ, 2002. The Cerrados of Brazil. Ecology and Natural History of a Neotropical Savanna. New York: Columbia University Press.

Parsons PA, 1991. Biodiversity conservation under global climatic-change - the insect Drosophila as a biological indicator. Global Ecology and Biogeography Letters, 1:77-83.

Parsons PA, 1995. Evolutionary Response to Drought Stress - Conservation Implications. Biological Conservation, 74:21-27.

Powell JR, 1997. Progress and Prospects in Evolutionary Biology: the Drosophila Model. New York: Oxford University Press.

Roque F, Figueiredo R \& Tidon R, 2006. Nine new records of drosophilids in the Brazilian savanna. D IS, 89:1-5.

Silva JMC, 1997. Endemic bird species and conservation in the Cerrado region, South America. Biodivers Conserv, 6: $435-450$

Silva JMC \& Bates JM, 2002. Biogeographic patterns and conservation in the South America Cerrado: a tropical savanna hotspot. BioScience, 52:225-233.

TaxoDros, 2010. The database on taxonomy of Drosophilidae. Bächli G (org). [2010 April 18]. Available from: http:// taxodros.unizh.ch/.

Tidon R, 2006. Relationships between drosophilids (Diptera, Drosophilidae) and the environment in two contrasting tropical vegetations. Biological Journal of the Linnean Society, 87:233-248.

Tidon R, Leite DF \& Leão BFD, 2003. Impact of the colonizationof Zaprionus (Diptera, Drosophilidae) in different ecosystems of the Neotropical Region: 2 years after the invasion. Biological Conservation, 112:299-305.

Received: May 2010

First Decision: May 2010

Accepted: May 2010 